\title{
Long-term follow-up of unsuccessful coil embolisation in Osler-Weber-Rendu syndrome
}

\author{
Pichapong Tunsupon, Pojchawan Yampikulsakul, Natdanai Punnanithinont
}

Department of Medicine, University at Buffalo State University of New York School of Medicine and Biomedical Sciences, Buffalo, New York, USA

\section{Correspondence to} Dr Pichapong Tunsupon, ptunsupon@gmail.com

Accepted 27 January 2016

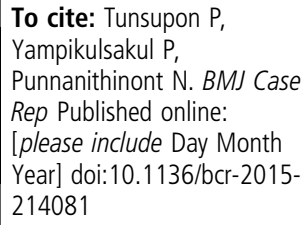

CrossMark

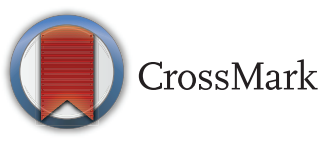

\section{DESCRIPTION}

A 22-year-old woman was referred for management of intermittent haemoptysis. She had been diagnosed with hereditary haemorrhagic telangiectasia (HHT) when she was 5 years old and had undergone coil embolisation for treatment of pulmonary arteriovenous malformation (PAVM) at the ages of 6,11 and 21 years. CT of the chest revealed multiple areas of PAVM and enhanced consolidation confined to the left lower lobe, and a large PAVM in the area that was previously coiled (figure 1). Pulmonary arteriogram was demonstrated (figures 2 and 3). There was no active site of contrast leaking, thus the patient was vigilantly monitored in the intensive care unit. However, she continued to experience intermittent haemoptysis. In the absence of randomised controlled trials for most of the available treatments for PAVM, the patient underwent a left partial lobectomy to prevent lifethreatening complications such as massive haemoptysis, brain abscess, paradoxical embolism and ischaemic stroke.

The persistent pattern, defined as continuous perfusion of the PAVM, is demonstrated by

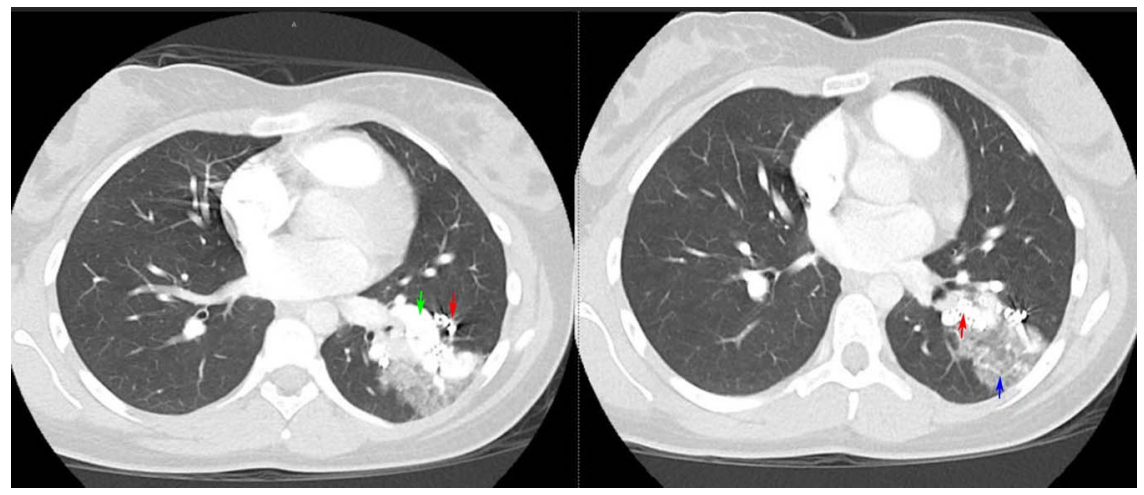

Figure $1 \mathrm{CT}$ of the chest demonstrating multiple bilateral pulmonary arteriovenous malformation (PAVM). Note an area of enhanced consolidation (blue arrow), a large PAVM (green arrow) and evidence of previous coiling attempts confined to the left lower lobe (red arrow).

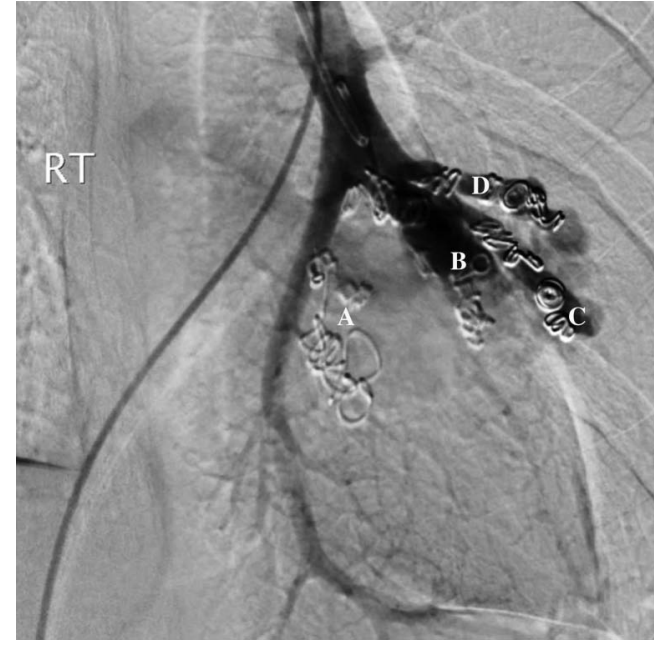

Figure 2 Left lower lobe pulmonary arteriogram demonstrating no active haemorrhage and no abnormal parenchymal stain. A indicates a complete cessation of blood flow from previous treatment with coil embolisation. B and C indicate recanalisation of feeding arteries that were previously coiled. D indicates recanalisation of a coiled segmental artery.

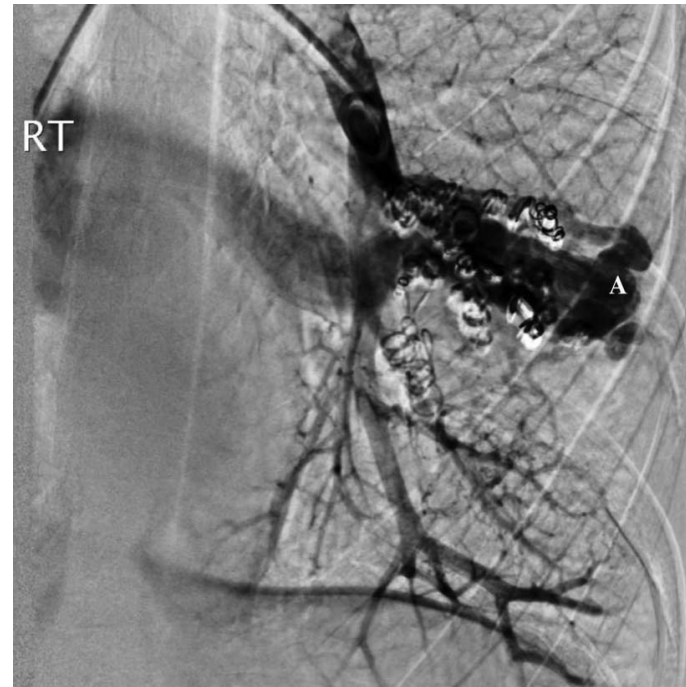

Figure 3 Left lower lobe pulmonary arteriogram demonstrating $(A)$ a large complex pulmonary arteriovenous malformation (PAVM) containing more than one segmental artery connecting the aneurysmal sac to the draining veins. 
pulmonary arteriogram. Previous studies have categorised the mechanism of a persistence pattern variously as recanalisation, ${ }^{1}$ incomplete treatment, ${ }^{2}$ pulmonary-to-pulmonary reperfusion ${ }^{2}$ and rare systemic-to-pulmonary reperfusion. ${ }^{3}$ Recanalisation is the most common persistence pattern of simple PAVM, and is associated with a high success rate after re-treatment with embolisation. ${ }^{1}$ We highlight an uncommon persistent pattern

\section{Learning points}

- Recanalisation occurs despite multiple treatments with coil embolisation, to form a large complex pulmonary arteriovenous malformation (PAVM). It is the most common persistent pattern of recurrent PAVM.

- Surgical excision is the treatment of choice for patients with symptomatic PAVM who carry a diagnosis of Osler-Weber-Rendu syndrome and fail multiple treatments with coil embolisation in 15 years follow-up. attributed to recanalisation of the two feeding arteries and a segmental artery that were previously coiled, forming a large complex PAVM. Surgical excision is the treatment of choice for patients with symptomatic PAVM in HHT (Osler-Weber-Rendu syndrome) who fail multiple treatments with coil embolisation in 15 years follow-up.

Contributors PT, PY and NP prepared the manuscript and/or revised it critically for important intellectual content and approved the final version before submission to the journal.

Competing interests None declared.

Patient consent Obtained.

Provenance and peer review Not commissioned; externally peer reviewed.

\section{REFERENCES}

1 Woodward CS, Pyeritz RE, Chittams JL, et al. Treated pulmonary arteriovenous malformations: patterns of persistence and associated retreatment success. Radiology 2013;269:919-26.

2 Lee DW, White RI Jr, Egglin TK, et al. Embolotherapy of large pulmonary arteriovenous malformations: long-term results. Ann Thorac Surg 1997;64:930-9; discussion 9-40.

3 Isoda S, Suzuki A, Kajiwara $H$, et al. [Pulmonary arteriovenous malformation with systemic blood supply]. Nihon Kyobu Geka Gakkai Zasshi 1992;40:1304-8.

Copyright 2016 BMJ Publishing Group. All rights reserved. For permission to reuse any of this content visit http://group.bmj.com/group/rights-licensing/permissions.

BMJ Case Report Fellows may re-use this article for personal use and teaching without any further permission.

Become a Fellow of BMJ Case Reports today and you can:

- Submit as many cases as you like

- Enjoy fast sympathetic peer review and rapid publication of accepted articles

- Access all the published articles

- Re-use any of the published material for personal use and teaching without further permission

For information on Institutional Fellowships contact consortiasales@bmjgroup.com

Visit casereports.bmj.com for more articles like this and to become a Fellow 